\title{
Development and Performance Evaluation of a Semi-Automatic Pineapple Peeling Machine
}

\author{
A.V. Anjali*, P.K. Anjitha, K.P. Neethu, A. Arunkrishnan, \\ P. Abdul Vahid and Santhi Mary Mathew \\ Department of Food and Agricultural Process Engineering, Kelappaji College of \\ Agricultural Engineering and Technology, Kerala Agricultural University, \\ Thavanur, Kerala, 679473, India \\ *Corresponding author
}

\section{A B S T R A C T}

\section{Keywords}

Pine apple, Peeling, Wedge shaped blade

Article Info

Accepted:

04 October 2019

Available Online:

10 November 2019
Pineapple is one of the major fruit produced in India. The major problem related with the processing of pineapple is peeling. Peeling of pineapple manually is a time consuming, labour intensive process and causes drudgery, Therefore a simple, semi mechanical pineapple peeling machine which is easy to operate, maintain, and economical was fabricated. The peeler removes the peel effectively and makes further processing easy. The equipment consist of mainly three parts two motors, cutting blade and diameter adjustment system. One motor of $300 \mathrm{rpm}$ and $12 \mathrm{v}$ which control the movement of blade and another of $500 \mathrm{rpm}$ and $12 \mathrm{v}$ used to rotate pineapple. The wedge shaped cutting blade made from stainless steel square pipe having $0.1 \mathrm{~mm}$ thickness, $4 \mathrm{~mm}$ length and $2 \mathrm{~mm}$ width. The blade is attached to diameter adjustment system which facilitates the movement of blade according to shape of pineapple. The simultaneous movement of two motors helps in rotation of pineapple and upward as well as downward movement of blade, respectively. This results in peeling of pineapple. The designed pineapple peeler also proved to have a high efficiency $(99.3 \%)$ with less material loss $(1.69 \%)$ and capacity about $305.5 \mathrm{~kg} / \mathrm{hr}$.

\section{Introduction}

Fruits are good source of vitamins and minerals, without which human body cannot maintain proper health and develop resistant to disease. Nutritionist advises to take 60 to $85 \mathrm{~g}$ of fruit per day in addition to cereals and pulses. It also contains pectin, cellulose, vitamins and minerals.

In Kerala pineapple (Ananas comosus) which belongs to bromeliaceae family, is considered as the major fruit that can give a higher market profit. The main component of pineapple is 
water $(86 \mathrm{~g} / 100 \mathrm{~g})$, and it contains vitamins like vitamin $\mathrm{C}$, vitamin B1, vitamin B6, dietary fibers like pectin, sugar, minerals like copper, potassium etc. The major vitamin present is vitamin $\mathrm{C}$ which is the primary water soluble antioxidant of our body.

A group of sulfur containing proteolytic enzymes (bromelain) present in pineapple which makes faster digestion. The fresh pineapple rich in bromelain can be used for meat tenderization. It also has some anti inflammatory properties and anti clotting properties. Daily consumption of pineapple helps to fight against arthritis, indigestion, and worm infection. Presence of vitamin A helps in maintaining healthy mucus membrane, skin and vision. The presence of copper and potassium helps in red blood cells synthesis and controlling the blood pressure, respectively

The pineapple had become one of the main fruit items that generate profit in the market due its nutritional benefits. In every processing industry peeling process is done manually by the workers. The manual peeling process is done by bare hands and knifes just like we are doing at home. Peeling is one of the most crucial parts in processing of a pineapple and it needs lot of force and muscle usage due to its thick skin, also there is chance for human drudgery. In case of pineapple peeling the workers forced to take repetitive movements, which involve mainly the upper body part thus making the body vulnerable to back pain and other Muscular drudgery symptoms for workers. The most infected part is known as the carpel. If the processing duration increased the body part might not be able function well according to its usage. According to Mohamed, 2010 Pineapple peeling is a time consuming and labour intensive process which causes muscular drudgery. In Kerala there are a lot of small scale pineapple processing industries, but the lack of proper equipments for peeling leads to an inefficient processing. The available literature and visit conducted to various pineapple processing industries in Kerala revealed that there exist no viable equipments for the peeling of pineapple.

A Gineca machine and manual pineapple peeling, coring and slicing equipment were reported earlier but their working is much complicated and cause larger material loss in pineapple and also costly. So these machines are not being adopted for the use by the small scale processors of Kerala.

Therefore, it becomes necessary to design machineries for pineapple peeling which is simple in operation, easy to maintain and suitable for small scale industries, Kudumbasree's and self help groups to purchase. With this in mind, this project was taken up with the following objectives to develop a simple, semi automatic pineapple peeling machine which is easy to operate, maintain and economical and to evaluate the performance of the developed machine.

\section{Materials and Methods}

A semi automatic pineapple peeling machine was designed and developed (Figure. 1). The machine was fabricated in the workshop of the Department of agricultural processing and food engineering, KCAET Tavanur. The main components of the unit were Frame Assembly, Holding unit, Motor, Cutting Blade, Diameter Adjustment System, Frame covering.

\section{Frame Assembly}

Frame was fabricated by using GP (galvanized plane sheet) square pipe of $1.0 \mathrm{~mm}$ thickness and a width of $20.0 \mathrm{~mm}$. On to this frame assembly, other subassemblies like motor, holding unit, cutting blade, Diameter adjusting system were mounted. 


\section{Holding unit}

The machine consists of a Top holding unit and a bottom holding unit (Figure 2 and 3 ). The purpose of top holding unit is for rotating the pineapple. This holding unit is connected with the second motor. It is made up of SS with $62 \mathrm{~mm}$ diameter. The bottom holding unit consists of two main parts. One is a Stainless Steel circular section of $62 \mathrm{~mm}$ diameter and other is of Mild Steel section having a length $200 \mathrm{~mm}$ and a diameter of 25 mm threaded shaft.

This unit has a four leg nut mechanism for the purpose of adjusting length. When rotating the leg nut mechanism, the threaded shaft will move upward and downward through a slot provided at the bottom. In order to prevent the rotation of threaded shaft, a socket mechanism provided at the bottom for holding the shaft. Inside both holding units a cross shape blade of $60 \mathrm{~mm}$ length and a $1.0 \mathrm{~mm}$ thickness has provided for gripping purpose.

\section{Motor}

This machine is equipped with two motors called as first motor and second motor. First motor is having an rpm of 300 and 12 volts and the second motor are having $500 \mathrm{rpm}$ and 12 volts (Figure 4 ).

The purpose of first motor is for controlling the movements of blades to upward and downward where the function of second motor is to rotate the pineapple. When the switch is ON both motor will start to work.

Both forward and reverse connection has done for the upward and downward movement of the blades. The blade is always kept at the bottom position for the peeling purpose. The motor has been mounted on a metal sheet having $309 \mathrm{~mm}$ length, $100 \mathrm{~mm}$ width and a thickness of $3 \mathrm{~mm}$.

\section{Cutting blade}

A square pipe of SS cut and made in to a cutting edge of $40 \mathrm{~mm}$ length and $20 \mathrm{~mm}$ width (Figure 5). Cutting edge has been sharpened by using a file. The blade has been connected to the diameter adjusting system. The cutting blade helps to the peeling process.

\section{Diameter adjustment system}

The purpose of this diameter adjusting system is to set the blade with respect to various diameters of pineapples (Figure 6). The system has consisted of a horizontal shaft of $225 \mathrm{~mm}$ length and $10.5 \mathrm{~mm}$ width and having threads on it. A $45 \mathrm{~mm}$ length and $20 \mathrm{~mm}$ diameter of internal threaded socket mounded on it, also having a $60 \mathrm{~mm}$ diameter handle for the forward and backward movement of blade. An another horizontal shaft of length $85 \mathrm{~mm}$ placed inside and covered by $90 \mathrm{~mm}$ shaft connected to handle were the blade is mounted and its purpose is to set the blade on permanent position while the other shaft is rotating. System is connected on a vertical shaft of length $400 \mathrm{~mm}$, and width of 10.5 $\mathrm{mm}$. The purpose of the vertical shaft is to moving the Diameter Adjusting System to upward and downward for the purpose of pineapple peeling.

\section{Operational procedures}

Pineapples of different varieties and different maturity were selected from the shop. Making $16 \mathrm{~mm}$ and $20 \mathrm{~mm}$ cut from top and bottom respectively. Thus the crown of the pineapple has been removed. Fix the pineapple on holding unit with the help of four leg nut mechanism. After the proper fixation bring down the cutting blade to the bottom through the threaded rod, because the peeling process starts from the bottom and ends at the top. On the application of dc power supply both motors gets started, which leads to the 
rotational motion of screw threaded rod and the holding units. That means the electrical energy is converted to rotational motion. As a result of this rotation motion both pineapple and cutting blade will get a rotation motion and a two and fro motion respectively. Along with the movement of blade the diameter adjustments can also be done, so that the peeling process can be obtained according to the size and shape of the pine apple. Thus a mechanical work is done.

\section{Performance evaluation}

\section{Peeling efficiency}

Each sample of pineapple was subjected to peeling action. After the peeling was completed, the peels remaining on the pineapple were removed manually for each of the samples and their weights were noted.

Peeling efficiency was then calculated by using the formula, suggested by Singh and Shukla (1995).

Peeling Efficiency $=\frac{(y-x)}{x} \times 100$

Where $\mathrm{Y}$ is the weight of peel on pineapple, $\mathrm{X}$ is the weight of peel remaining on the pineapple which is removed by hand trimming after mechanical peeling.

\section{Material loss}

Material loss for each sample of pineapple was calculated based on following formula, suggested by Agrawal (1987).

Material loss $(\%)=\frac{(\mathrm{z})}{(\mathrm{w}+\mathrm{z})} \times 100$

Where $\mathrm{Z}$ is the weight of pineapple after mechanical peeling $(\mathrm{g})$ for canning purposes, $3 / 4$ of the eyes have to be removed.

\section{Capacity of the machine}

The capacity of the peeler, which is the number of $\mathrm{kg}$ pineapple produced by the machine in one hour was calculated by noting the weight of the peeled, cored pineapple produced and the time taken for the same. It was then expressed in $\mathrm{kg} / \mathrm{hr}$

Capacity $=$

$\mathrm{kg}$ of pinepplepeeled

time required for the peeling of the pineapple(hr)

\section{Results and Discussion}

The data presented in Table 1 showed the brief specifications of the raw material. The weight of the pineapple ranges from $1721 \mathrm{~kg}$ to 1627 $\mathrm{kg}$. The diameter varies from $80 \mathrm{~mm}$ to $95 \mathrm{~mm}$ and the length of pineapple varies between $180 \mathrm{~mm}$ to $200 \mathrm{~mm}$.

\section{Evaluation of Model}

The model was evaluated for its overall capacity, peeling efficiency and material loss

\section{Overall capacity}

Theoretical capacity was found to be 304.7 $\mathrm{kg} / \mathrm{hr}$. A time lag of 35 seconds for peeling to account for counting and opening the doorway and to take the pineapple from the clamped surface is taken for a skilled worker between successive feedings, so the effective capacity is $109.7 \mathrm{~kg} / \mathrm{hr}$. The actual capacity of the machine ranges between $108 \mathrm{~kg} / \mathrm{hr}$ to 111 $\mathrm{kg} / \mathrm{hr}$. Also the overall capacity of the machine ranges between $303 \mathrm{~kg} / \mathrm{hr}$ to $308 \mathrm{~kg} / \mathrm{hr}$.

The results are shown in the Table 2. The capacity of machine does not show a wide range difference, according to the change in weight of pineapple. Also the time taken for peeling might be changed based on the height or length of pineapple. 


\section{Peeling efficiency}

The peeling efficiency was calculated by using the formulae suggested by Singh and Sukhla (1995) and the average peeling efficiency was found to be $99.2 \%$. The results are shown in Table 3. Peeling efficiency is not changing according to the diameter of pineapple and weight of the pineapple. The efficiency value ranges from $99-100 \%$.

\section{Material loss}

As per the calculation the average material loss was found to be $1.73 \%$. The material loss ranges from 1.6 to $1.8 \%$. The results are shown in table 4 . The loss obtained from the equipment during peeling is very less while compared to other peelers and other peeling methods.
India is known as fruit basket of the world. Our country holds second position in fruit production and we are producing 45 MT per year. Post harvest losses in fruits are one of the most processing problems. About $35 \%$ of loss is happening due to improper processing method. A substantial return can be obtained by processing and marketing that product on small scale. The pineapple is one of the major fruit and India produce about 1438.5 T. A plenty of value added products of pineapple are available in our market. The major problem faced in the processing of pineapple is the peeling. The peel of the pineapple should be properly removed, so as to avoid the itching and allergy caused by the peel. The peel is generally thick and non uniform. Due to this reason there need a more force to remove the peel.

Table.1 specification of pineapple

\begin{tabular}{|c|c|c|c|}
\hline Sample & Weight $(\mathbf{k g})$ & Diameter $\mathbf{( m m})$ & Length $(\mathbf{m m})$ \\
\hline $\mathbf{1}$ & 1628.2 & 80.0 & 180.0 \\
\hline $\mathbf{2}$ & 1648.6 & 83.0 & 183.0 \\
\hline $\mathbf{3}$ & 1720.1 & 95.0 & 200.0 \\
\hline $\mathbf{4}$ & 1672.5 & 88.0 & 190.0 \\
\hline $\mathbf{5}$ & 1643.8 & 82.0 & 182.0 \\
\hline $\mathbf{6}$ & 1701.3 & 91.0 & 195.0 \\
\hline
\end{tabular}

Table.2 Overall capacity and actual capacity of pineapple peeling machine

\begin{tabular}{|c|c|c|c|c|}
\hline SI. No & $\begin{array}{c}\text { Weight Of Peeled } \\
\text { Pineapple (g) }\end{array}$ & $\begin{array}{c}\text { Time Taken for } \\
\text { Peeling }(\mathbf{s})\end{array}$ & $\begin{array}{c}\text { Overall Capacity }_{\left(\mathbf{k g h r}^{-1}\right)} \\
\text { ( })\end{array}$ & $\begin{array}{c}\text { Actual Capacity } \\
\left(\mathbf{k g h r}^{-1} \mathbf{)}\right.\end{array}$ \\
\hline $\mathbf{1}$ & 1628.2 & 19.0 & 308.4 & 108.5 \\
\hline $\mathbf{2}$ & 1648.6 & 19.5 & 304.4 & 108.9 \\
\hline $\mathbf{3}$ & 1720.1 & 20.4 & 303.4 & 111.7 \\
\hline $\mathbf{4}$ & 1672.5 & 19.8 & 304.0 & 109.87 \\
\hline $\mathbf{5}$ & 1643.8 & 19.5 & 303.4 & 108.58 \\
\hline $\mathbf{6}$ & 1701.3 & 20.1 & 304.7 & 111.15 \\
\hline & Average & & 304.7 & 109.7 \\
\hline
\end{tabular}


Table.3 Peeling efficiency of pineapple peeling machine

\begin{tabular}{|c|c|c|c|}
\hline SI. No & $\begin{array}{c}\text { Weight of peel on pineapple } \\
(\mathbf{g})\end{array}$ & Weight of peel remaining on pineapple (g) & Peeling efficiency (\%) \\
\hline $\mathbf{1}$ & 400.0 & 0.0 & 100.0 \\
\hline $\mathbf{2}$ & 430.0 & 3.9 & 99.1 \\
\hline $\mathbf{3}$ & 460.0 & 4.6 & 99.0 \\
\hline $\mathbf{4}$ & 440.0 & 4.0 & 99.0 \\
\hline $\mathbf{5}$ & 425.0 & 3.4 & 99.2 \\
\hline $\mathbf{6}$ & 451.0 & 4.2 & 99.0 \\
\hline & Average & & 99.2 \\
\hline
\end{tabular}

Table.4 Calculated material loss of peeling machine

\begin{tabular}{|c|c|c|c|}
\hline Sl.No & $\begin{array}{c}\text { Weight of peeled pineapple } \\
(\mathbf{g})\end{array}$ & $\begin{array}{c}\text { Weight of flesh obtained from the peel } \\
(\mathbf{g})\end{array}$ & Material loss (\%) \\
\hline $\mathbf{1}$ & 1228.2 & 20 & 1.6 \\
\hline $\mathbf{2}$ & 1218.6 & 21 & 1.69 \\
\hline $\mathbf{3}$ & 1260.1 & 23 & 1.79 \\
\hline $\mathbf{4}$ & 1232.5 & 21 & 1.7 \\
\hline $\mathbf{5}$ & 1218.8 & 22 & 1.8 \\
\hline $\mathbf{6}$ & 1250.3 & 23 & 1.8 \\
\hline Average & & & 1.73 \\
\hline
\end{tabular}

Fig.1 Semi automatic pineapple peeling machine

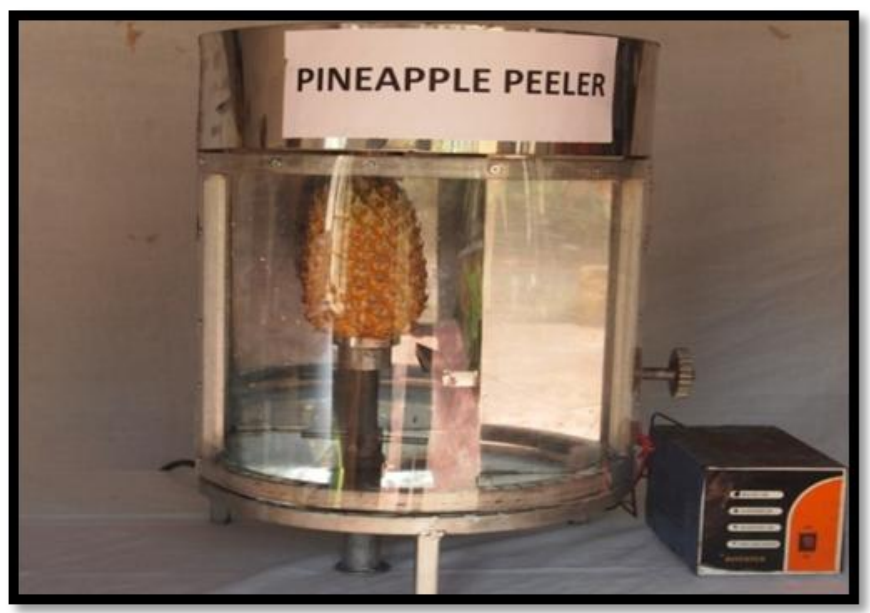


Fig.2 Upper holding unit

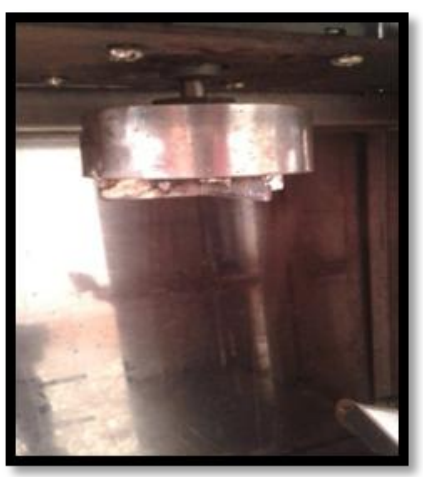

Fig.3 Bottom holding unit

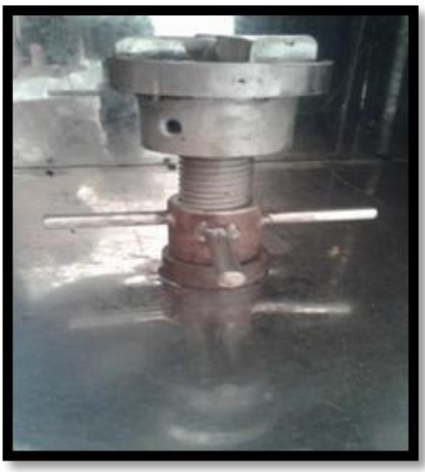

Fig.4 Motor

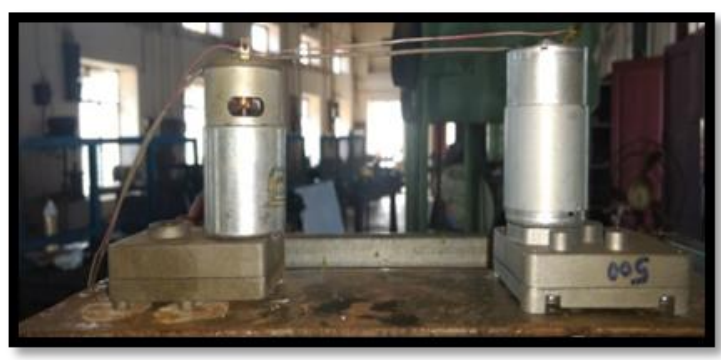

Fig.5 Cutting blade

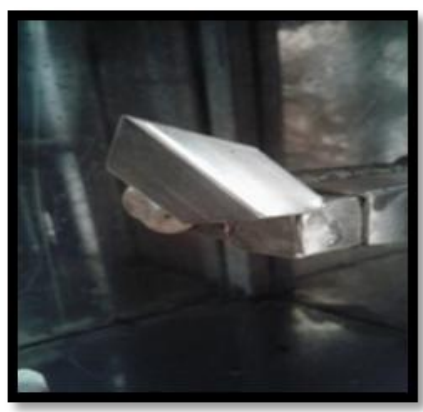

Fig.6 Diameter adjusting system

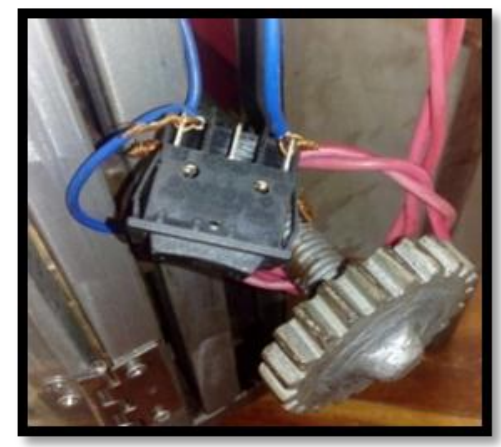


In most of the peeling is done by using knives. It may cause muscular disease and also it is a labor intensive and time consuming process. Though some of the pineapple peeling machine are available in market they are exorbitantly, priced, not that much flexible, not at all user friendly. Most of them made up of plastics. So that they are has been less strength. Therefore, it becomes necessary to develop a machine for pineapple peeling process which is simple in operation, easy to maintain and suitable for small scale industry.

A pineapple peeling machine was developed and fabricated, it consist of mainly frame assembly, holding unit, driving unit, diameter adjusting system, cutting unit(blade) these part are mounted on a frame assembly. The driving unit consists of two motor which helps in rotation of pineapple and upward and downward movement of blade. Pineapples are different in their size and symmetry. So during peeling time the wastage is more so that it having a diameter adjusting system which facilitate the movement of blade according to the size of pineapple.

The overall capacity of newly developed machine is $305.4 \mathrm{~kg} / \mathrm{hr}$, and peeling efficiency is $99.3 \%$. While comparing the capacity with the manual peeling process it found that the material loss is very less i.e., about $1.69 \%$.

\section{References}

Agrawal, Y.C., Singhvi, A., and Sodhi, R.S. 1983. Development of an abrasive brush-type ginger peeling machine. $J$. Agric. Eng. 384(11): 179-182.

National Horticulture Board - Horticultural statistics at a glance. 2015. Oxford university press publication, New Delhi, India.

Pandey, P.H. 1997. Post harvest technology of fruits and vegetables, Saroj Prakasan, Alahabad, PP: 100-110.

Pineapple-An industrial profile 1985. CFTRI, Mysore.

Joy. P.P. 2013. Pineapple sector in kerala; status, opportunities, challenges and stackholders. KAU, Vazhakulam. Available; $\quad$ http://www.kau.edu/ prsvkm.pdf [17 Jan 2017].

Singh, K.K. and Shukla, B.D. 1995. Abrasive peeling of potatoes. J. Food. Eng. 26: 431-442.

\section{How to cite this article:}

Anjali, A.V., P.K. Anjitha, K.P. Neethu, A. Arunkrishnan, P. Abdul vahid and Santhi Mary Mathew. 2019. Development and Performance Evaluation of a Semi-Automatic Pineapple Peeling Machine. Int.J.Curr.Microbiol.App.Sci. 8(11): 325-332.

doi: https://doi.org/10.20546/ijcmas.2019.811.041 